\title{
Obesity and the Risk of Gastrointestinal Cancers
}

\author{
Jacek Karczewski ${ }^{1}$ (D) B Beata Begier-Krasińska ${ }^{2} \cdot$ Rafał Staszewski $^{2} \cdot$ Edyta Popławska $^{3}$. \\ Katarzyna Gulczynska-Elhadi ${ }^{3} \cdot$ Agnieszka Dobrowolska $^{4}$
}

Received: 24 October 2018 / Accepted: 26 March 2019 / Published online: 9 April 2019

(c) The Author(s) 2019

\begin{abstract}
Obesity is a risk factor for all major gastrointestinal cancers. With the rapid increase in the prevalence of obesity worldwide, this link could lead to an elevated burden of cancers of the digestive system. Currently, three main mechanisms explaining the link between excess adiposity and gastrointestinal cancer risk are being considered, including altered insulin signaling, obesity-associated chronic low-grade inflammation, and altered sex hormone metabolism, although new potential mechanisms emerge. This review is aimed to present our current knowledge on biological mechanisms involved in adiposity-related gastrointestinal carcinogenesis supported by results collected in epidemiological studies.
\end{abstract}

Keywords Obesity $\cdot$ Gastrointestinal cancer $\cdot$ Adiposity $\cdot$ Risk factor

\section{Introduction}

Obesity, defined as a disproportionate body weight for height with an excessive accumulation of adipose tissue, is considered a twenty-first-century epidemic [1]. According to WHO, $>1.9$ billion adults were estimated to be overweight (defined as a BMI $\geq 25 \mathrm{~kg} / \mathrm{m}^{2}$ ) globally in 2016, of which 650 million were obese $\left(\mathrm{BMI} \geq 30 \mathrm{~kg} / \mathrm{m}^{2}\right)$ [2]. Excess adiposity commonly leads to metabolic disorders, chronic lowgrade inflammation, and altered production of steroid hormones [3]. These pathophysiological effects have been also associated with cancer development and progression $[4,5]$. In 2016, the International Agency for Research on Cancer (IARC) reported that 16 types of cancer are probably or convincingly associated with excess adiposity, making obesity the second leading cause of cancer after smoking [6]. The IARC report concluded that the absence of excess body fat reduces risk of most cancers. It is important to note that several obesity-associated cancers, such as those of the breast and visceral organs, arise either within or adjacent to adipose depots suggesting that altered adipose biology, locally and systemically promotes cancer development. According to IARC and the World Cancer Research Fund (WCRF) Continuous Update Project, the excess adiposity is a cause or probable risk factor for gastrointestinal cancers, including the pancreas, liver, esophagus, colorectum, stomach cardia, and gallbladder [6-12]. The rapid increase in the prevalence of obesity worldwide could lead to an elevated burden of gastrointestinal cancers.

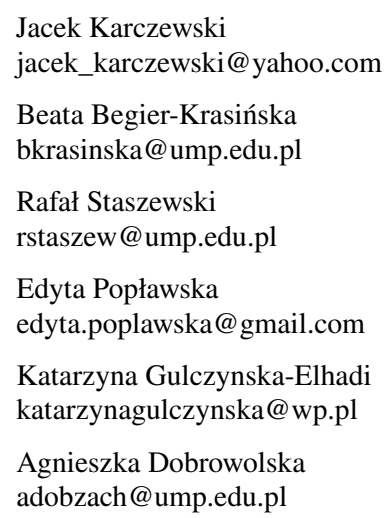

1 Department of Environmental Medicine/Department of Gastroenterology, Human Nutrition and Internal Medicine, Poznan University of Medical Sciences, Fredry 10, 61-701 Poznan, Poland

2 Department of Hypertensiology, Angiology and Internal Medicine, Poznan University of Medical Sciences, Fredry 10, 61-701 Poznan, Poland

3 AI Centrum Medyczne, Swietojanska 1, 61-113 Poznan, Poland

4 Department of Gastroenterology, Human Nutrition and Internal Medicine, Poznan University of Medical Sciences, Fredry 10, 61-701 Poznan, Poland 
Although gastrointestinal cancers arise from distinct tissue origins and therefore represent different diseases, they share some common characteristics [13]. For instance, each organ-specific form of gastrointestinal cancer seems to have subtypes that reflect mesenchymal gene signature, immune cell infiltration, and metabolic alterations, with additional gene signatures reflecting the epithelial tissue of origin within each distinct subtype [14]. Gastrointestinal cancers also frequently share some metabolic characteristics, such as increased uptake of glucose and the conversion of glucose to lactate [15], although pancreatic tumors show a unique dependency on metabolic pathways for branched-chain amino acids [16]. Studies of colorectal cancer (CCR) also show that the carcinogenesis-promoting effect of excess energy balance might differ between different tumor subtypes, with findings suggesting that a high BMI has a stronger effect on tumor subtypes that maintain better intestinal differentiation [17]. Altogether, these features give insight into the relationship between excess adiposity and gastrointestinal cancers and might help to determine potential therapeutic targets. This review is aimed to outline main hypotheses explaining the link between obesity and gastrointestinal cancer risk that are currently under consideration: i) altered insulin and insulin-like growth factor 1 (IGF-1) signaling, ii) obesityassociated chronic low-grade inflammation, and iii) altered sex hormone metabolism [Fig. 1].

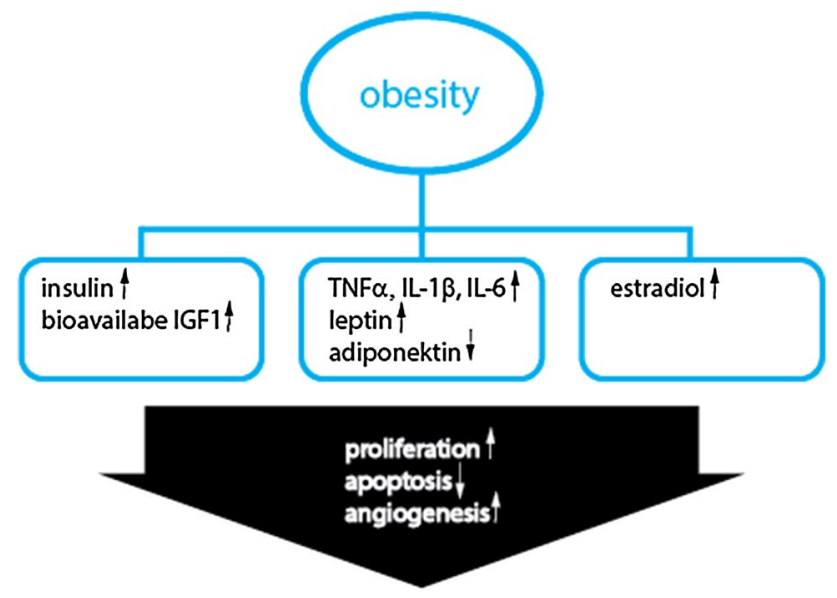

tumor development

Fig. 1 Three main mechanisms linking obesity and gastrointestinal cancers. Obesity is associated with altered insulin and insulin-like growth factor 1 signaling, chronic subclinical adipose tissue inflammation and altered sex hormone metabolism. $I G F-1$, insulin-like growth factor-1; $I L$, interleukin; $T N F$, tumor necrosis factor

\section{Altered Insulin and Insulin-Like Growth Factor 1 Signaling}

The alterations of cellular metabolism are an emerging hallmark of cancer [13]. Reduced dependence on mitochondrial respiration and increased aerobic glycolysis to generate substrate required for a rapid cell proliferation are common features of gastrointestinal cells [15]. Associated with this shift, the so-called Warburg effect is also an increased dependence on adequate systemic levels of glucose and other nutrients, similar to obesity-driven metabolic alterations [15]. This "two-compartment coupling metabolism," in which signals from cancer cells drive aerobic glycolysis in neighboring stromal cells for efficient energy production, is called the reverse Warburg effect; systemic metabolic alterations also influence this effect [18]. Thus, the obesity-driven systemic metabolic alterations can influence cancer cell-intrinsic metabolism. Findings also suggest concomitant metabolic changes in stromal cells in the microenvironment, particularly cancerassociated fibroblasts, that contribute energy-rich fuels, such as pyruvate, fatty acids, and lactate, to drive mitochondrial oxidative phosphorylation of cancer cells during periods of high ATP demand [19]. Changes in systemic metabolic factors, including high circulating levels of insulin and IGF-1, seem to be important factors contributing to gastrointestinal cancer development.

Hyperinsulinemia and insulin resistance are often present in individuals with obesity, and BMI and waist circumference are both associated with elevated circulating levels of insulin or C-peptide (C-p), which is a marker of insulin secretion [20]. By binding to its cognate receptor (insulin receptor; IR) or the insulin-like growth factor 1 receptor 1 (IGF-1R), insulin activates the phosphoinositide 3-kinase (PI3K), which is a target of rapamycin (mTOR) and mitogen-activated protein kinase (MAPK) signaling pathways, exerting its metabolic and cellular growth effects [21]. Activation of IR and IGF-1R triggers cancerrelevant intracellular signaling cascades including those required for mitogenesis, anti-apoptosis, angiogenesis, and tumor-associated lymphangiogenesis, which favor tumor development and spread [22]. Hyperinsulinemia was shown to induce the development of aberrant crypt foci, which are thought to be the earliest neoplastic lesions in colorectal carcinogenesis, and the proliferation of colorectal epithelial cells in rodent models [23]. Additionally, IR expression is markedly elevated in colonic and hepatic tumor cells, particularly the A isoform (IR-A) that is involved in prenatal development but that also exhibits strong mitogenic effect, whereas expression of IR-B isoform, which has an important role in metabolism, was shown to be reduced in colorectal and liver tumor cells 
[24]. Insulin might also affect cancer development indirectly through modulation of other hormonal pathways. For instance, in hyperinsulinemia, sex hormone-binding globulin (SHBG) levels are significantly reduced, leading to elevated free estradiol levels, which might increase risk of cancer development [25]. Despite these experimental data, epidemiological studies investigating the link between hyperinsulinemia and CRC risk have yielded so far inconclusive results. Various prospective studies have shown the association between fasting circulating insulin levels and CRC, although this link was weakened after statistical adjustment for other CRC risk factors [26-28]. A positive association of circulating C-p levels with CRC risk was also reported in multiple studies [29-33], and a meta-analysis of these results showed a pooled odds ratio of 1.35 (95\% CI 1.12-1.63) for the individuals with the highest versus lowest levels of C-p [33]. Analysis of data gathered in the European Prospective Investigation into Cancer and Nutrition (EPIC) study demonstrated that individuals with normal BMI $\left(<25 \mathrm{~kg} / \mathrm{m}^{2}\right)$ but with elevated C-p levels were at a higher risk of CRC than those with a normal BMI and without elevated C-p levels and were at an equivalent risk of CRC to individuals who were overweight or obese (BMI $\geq 25 \mathrm{~kg} / \mathrm{m}^{2}$ ) with higher C-p levels [34]. However, overweight or obese individuals without elevated C-p levels were not at increased risk of CRC development. Overall, these findings support the association of hyperinsulinemia with CRC risk independent of body size [34].

As for other gastrointestinal cancers, a pooled analysis of five prospective studies reported that higher fasting circulating insulin levels were associated with elevated pancreatic cancer risk [35]. This result was further supported by a Mendelian randomization analysis, which reported that a 1 SD increment in genetically predicted fasting circulating insulin levels was associated with a $66 \%$ higher risk of pancreatic cancer development (relative risk (RR) 1.66, 95\% CI 1.05-2.63) [36]. An investigation nested within the EPIC cohort reported a greater than threefold higher hepatocellular carcinoma (HCC) risk among participants in the highest versus lowest-third group of C-p levels, while no relationship was found between circulating C-p levels and pancreatic cancer risk $[37,38]$. A nested case-control study conducted in Japan reported a positive association between circulating insulin levels and gastric cancer development [39]. As for esophageal cancer, no prospective studies have been conducted so far investigating the association with hyperinsulinemia.

Insulin can stimulate the synthesis of IGF-1, which is a peptide hormone that shares extensive structural similarity with insulin and can promote cellular proliferation through the activation of the PI3K/Akt/mTOR and Ras/Raf/ MAPK pathways [40]. Various epidemiological studies have investigated a possible link between pre-diagnostic circulating IGF-1 levels and CRC risk. The results of meta-analysis of ten prospective studies showed a modest positive association between circulating IGF-1 levels and CRC risk (OR per $1 \mathrm{SD}$ increment 1.07 ; 95\% CI 1.01-1.14) [41]. For other gastrointestinal cancers, the data are limited and inconclusive.

\section{Chronic Adipose Tissue Inflammation}

Obesity is considered a chronic low-grade inflammatory state characterized by progressive infiltration of adipose tissue by M1-macrophages, CD8+ T cells, natural killer (NK) cells, B cells, and increased adipose secretion of proinflammatory cytokines/adipokines such as tumor necrosis factor-alpha (TNF- $\alpha$ ), interferon-gamma (IFN- $\gamma$ ), interleukin-1-beta (IL-1 $\beta$ ), IL-6, monocyte chemoattractant protein 1 (MCP-1), and leptin [42-44]. Overall, the predominant anti-inflammatory T helper 2 (Th2)-like immune cell phenotype in healthy, lean individuals is lost with obesity, and the ensuing pro-inflammatory state leads to a dysregulation of immune homeostasis. The initial trigger for the inflammation is not fully understood, but most likely it is associated with a homeostatic stress caused by a positive energy balance and an overall hyper-anabolic state, particularly in adipocytes [42, 43]. Several potential mechanisms responsible for initiation of adipose tissue inflammation in obesity have been suggested, including (i) intestinal antigens such as lipopolysaccharide (LPS); (ii) various dietary components and metabolites, such as free fatty acids and glucose; (iii) signals associated with adipocyte death; (iv) hypoxia; (v) mechano-transduction resulting from interactions between the hypertrophic adipocytes and the extracellular matrix [42]. Although $10-15 \%$ of individuals with obesity might remain free of metabolic abnormalities and be "metabolically healthy," they commonly develop systemic inflammation $[45,46]$.

Multiple studies have revealed that chronic inflammation predisposes to various forms of cancer, including those located in gastrointestinal track. It has been observed that nearly all malignant lesions of gastrointestinal tract contain an immune cell infiltrate [47]. The nuclear factor- $\mathrm{KB}$ (NF$\kappa \mathrm{B})$, which plays a key role in inflammation, has also been shown to activate signaling pathways promoting malignancy [48, 49]. Inflammation, itself a microenvironmental hallmark of cancer, might be causally related to cancer development through various mechanisms, such as production of free radicals, suppression of the immune system, hypoxia or aberrant cell signaling, and upregulation of proliferative and anti-apoptotic pathways as well as angiogenesis and cell migration [50]. These adipose-driven processes are hypothesized to alter cancer cell metabolism and affect the cancerpromoting processes of invasion, metastasis, and immune clearance [51]. Visceral adipose tissue (VAT) is generally 
more bioenergetically active than subcutaneous adipose tissue (SAT), and obesity-driven excess of VAT has been associated with an increased risk of several gastrointestinal cancers [51]. VAT, which includes central depots such as omentum, mesenteric, epiploic, gonadal, epicardial, and retroperitoneal fat pads, is also thought to be a key source of obesity-derived inflammation [52]. The largest VAT depot is the omentum, the so-called fatty apron that connects the stomach and colon and lies anterior to the intestines. Importantly, VAT is also linked to the liver via portal vein drainage, and the VAT-liver axis is thought to account for the greater influence that VAT has on insulin resistance and inflammation compared with SAT [53]. In lean individuals, the liver maintains immunological tolerance by producing anti-inflammatory factors, predominantly IL-10, with selective expansion of hepatic Treg cells; however, it usually loses its tolerogenic status under excess adiposity conditions [54]. The portal hypothesis describes how the liver is directly exposed to increasing amounts of free fatty acids and proinflammatory factors released from VAT directly into the portal vein of individuals with visceral obesity, increasing the risk of liver inflammation and insulin resistance, and ultimately promoting gastrointestinal carcinogenesis [55].

A growing number of epidemiological studies have investigated the causal relationship between obesity-associated inflammation and gastrointestinal cancers. Multiple prospective cohort studies have investigated the possible link between levels of circulating C-reactive protein (CRP), a non-specific marker of systemic inflammation, and CRC risk. For instance, the results of a meta-analysis including more than 4500 individuals with CRC showed that the risk of CRC development was increased by $12 \%$ for every unit change in the natural log for CRP concentration [56]. This relationship was supported by a Mendelian randomization analysis that showed that a genetically predicted twofold doubling of circulating CRP levels was associated with higher risk of CRC development (OR 1.74; 95\% CI 1.06-2.85) [57].

Association of various adipokines and cytokines with CRC risk has been also investigated in several prospective studies. Adiponectin that is downregulated in obesity (mainly by insulin and estrogens [58]) has been linked to lower CRC risk [59]. It is the most abundant adipokine, secreted mainly from VAT. Of importance to cancer development, adiponectin may have indirect effects, sensitizing cells to insulin or through anti-inflammatory actions. Adiponectin may also sequester growth factors at the pre-receptor levels or by binding to adiponectin receptor 1 (ADIPOR1) and ADIPOR2, activating AMP-activated protein kinase (AMPK) while inhibiting ERK1 and ERK2, PI3K, PI3K-AKT, WNT- $\beta$-catenin, NF-KB and Janus kinase 2 (JAK2)-STAT3 signaling. Collectively, these effects result in reduced fatty acid and protein synthesis, decreased cellular growth, proliferation and DNA mutagenesis and increased cell cycle arrest and apoptosis, thus negatively influencing carcinogenesis [60-62]. By contrast, leptin, another adipokine, is upregulated in obesity by insulin to signal suppression of appetite [63]. It has extensive immunomodulatory roles through the stimulation of pro-inflammatory cytokines including IL-6, TNF- $\alpha$, IL-8, and IL-12 from macrophages, dendritic cells, and natural killer (NK) cells, as well as through Th1-type cell response [63]. Circulating levels of leptin were positively associated with colon cancer (OR for higher vs lowest quartile 2.72; 95\% CI 1.44-5.12) but not with rectal cancer [64]. In patients with cancer, leptin was demonstrated to promote mitogenic, anti-apoptotic, and pro-angiogenic [by itself and in synergy with vascular endothelial growth factor (VEGF)] pathways that are involved in carcinogenic process $[60,65]$. Leptin receptor $b(\mathrm{LRb})$, the only long form of at least four existing splice variants, has an intracellular domain of sufficient length to provide full signal-transducing capabilities and activates PI3K, MAPK, and signal transducer and activator of transcription (STAT) signaling, which are critical pathways involved in cell survival, proliferation, and differentiation [66]. Another study showed positive association of leptin, IL-6, and plasminogen activator inhibitor 1 (PAI1) levels and inverse association of adiponectin with the risk CRC development [67]. Inverse association of CRC risk has been also reported to soluble receptors of leptin and IL-1 $\beta[67,68]$, suggesting altogether that regulators of pro-inflammatory mediators signaling and availability modify CRC development. Data on possible association of circulating pro-inflammatory cytokines and adipokines with other gastrointestinal cancers are rather limited.

A study based on pooled data from five cohorts indicated the association of higher circulating adiponectin levels with lower pancreatic cancer risk (OR for the highest vs lowest quintile 0.66\%; CI 0.44-0.97), while it failed to find any link between circulating levels of CRP and IL-6 and pancreatic cancer risk [69]. A similar inverse association for adiponectin and pancreatic cancer was also found in the EPIC cohort, but only among non-smokers [37]. The EPIC study also reported the link between higher levels of circulating CRP (OR per doubling concentrations 1.22; 95\% CI 1.02-1.46) and IL-6 (OR per doubling concentrations $1.90 ; 95 \%$ CI 1.30-2.77) and elevated risk of HCC [38]. One nested case-control study conducted in Japan also reported a positive association for IL-6 with HCC but did not confirm a relationship for CRP [70]. The abovementioned EPIC study also reported a positive relationship for circulating CRP levels and greater gallbladder cancer risk (OR per doubling concentrations $1.55 ; 95 \% \mathrm{CI}$ 1.15-2.08) [38]. 


\section{Altered Sex Hormone Metabolism}

Sex hormones, a subgroup of steroid hormones, have been reported to modify the risk of several cancers, particularly sex-specific tumor types, such as postmenopausal breast, endometrial, and ovarian cancers. In both men and postmenopausal women, adipose tissue is the primary source of estrogen synthesis. Excess adiposity has been associated with higher circulating levels of endogenous estradiol and estrone due to the higher rates of conversion of androgenic precursors to estradiol through increased aromatase enzyme activity in peripheral adipose tissue (a process known as aromatization) [71]. At the same time, obesity is also associated with hyperinsulinemia, which results in reduced hepatic synthesis of sex hormone-binding globulin (SHBG), a principle transporter for sex steroid hormones, and increases in bioavailable concentrations of estradiol and testosterone [72]. Importantly, incidences of gastrointestinal cancers differ among sexes and are more frequent in men, suggesting a sex hormone-mediated mechanism in their etiology. Estrogen receptor- $\beta$ (ER $\beta)$ has been shown to have an important role in the biological activity of estrogens in gastrointestinal tissues. Various in vitro studies have demonstrated that expression of ER $\beta$ inhibits proliferation in colon cancer [73] and pancreatic cancer [74]. In xenograft mouse studies, ER $\beta$ inhibits $M y c$ expression and colon tumor growth [73]. It has been observed that the expression of ER $\beta$ is low in human colon cells and is inversely associated with colon cancer stage [75], suggesting a role in disease progression. Interestingly, recent report suggests that individual differences in $\mathrm{ER} \alpha$ and ER $\beta$ expression affect whether estradiol has proinflammatory or anti-inflammatory effects on colon, with this effect also probably occurring in other gastrointestinal tract tissue [76]. However, epidemiological data supporting the association of endogenous sex hormones and gastrointestinal cancer are limited.

One nested case-control study of postmenopausal women not using menopausal hormone therapy reported that higher levels of endogenous circulating estradiol and estrone were associated with lower CRC risk, while the levels of SHBG were positively related to CRC risk [77]. Other studies investigating the association of circulating estrogen levels with CRC risk were inconclusive [27, 78, 79]. One of these studies found that a higher ratio of circulating estradiol to testosterone levels, which reflects a higher activity of aromatase, the enzyme involved in biosynthesis of estradiol from testosterone, was associated with lower risk of CRC development [79]. Results for gastric cancer are inconclusive but tend to show that estrogens might also decrease the risk of carcinogenesis [80]. As for other gastrointestinal cancers, there is limited evidence from clinical trials that sex hormones, such as estrogen, progestin, or testosterone, have a role in the development of cancers [81-84].

\section{Other Potential Mechanisms}

\section{Intestinal Dysbiosis}

Various studies have demonstrated that excess adiposity is associated with intestinal dysbiosis [85]. Generally, microbiome of individuals with obesity is less diverse and has altered ratio of the two major gut phyla: Bacteroidetes and Firmicutes. Characteristic increase in Firmicutes and decrease in Bacteroidetes result in a microbiota with an improved ability to harvest dietary energy [85]. Obesityassociated dysbiosis also results in decreased production of anti-inflammatory short-chain fatty acids, particularly butyrate, which additionally exhibits anti-tumor effects via modulation of various G-protein-coupled receptors (GPCRs) and inhibition of histone deacetylases [86-88]. Such changes in microbiome diversity and metabolites can result in local inflammation and increased intestinal permeability, leading to enhanced leakage of intestinal antigens, including lipopolysaccharide (LPS) from Gram-negative bacteria-a condition termed metabolic endotoxemia [89, 90]. LPS in turn may initiate an inflammatory cascade via activation of pattern recognition receptors (PRRs), such as toll-like receptor 4 (TLR4) in adipocytes and macrophages, leading to the increased expression of pro-inflammatory cytokines and chemokines in adipose tissue $[89,91]$. Physiologically, LPS is continuously released to the intestine lumen by the death of Gram-negative bacteria and then translocated into intestinal cells through a TLR-dependent mechanism [92], and then transported in the circulation by a mechanism involving chylomicrons synthesized from epithelial intestinal cells in response to fat ingestion, although normally this process is adequately managed by the immune system and detoxification mechanism [93]. However, in individuals with obesity and T2DM, plasma LPS levels are at least doubled compared with those in healthy individuals, even in a fasted state [89, 94, 95]. LPS could be therefore an important inflammatory trigger, particularly in VAT, or might just amplify the effects of an earlier inflammatory trigger. Therefore, given the known role that chronic inflammation has in the progression of many cancers, it is plausible that obesity-induced intestinal dysbiosis is a contributing factor in the link between obesity and gastrointestinal cancers. Importantly, recent findings point toward the metabolic activity of the intestinal microbiota (producing butyrate, propionate, or altering bile acids) as important mechanism leading to development and progression of various gastrointestinal cancers [88].

\section{Intestinal Hormones}

Intestinal hormones are also emerging mediators of the obesity-gastrointestinal cancer association. For instance, ghrelin, a peptide hormone produced by the fundic glands of 
the stomach, exhibits various metabolic and inflammatory functions, such as appetite regulation, promotion of fat storage, and inhibition of pro-inflammatory cytokine expression [96]. Lower circulating ghrelin levels have been observed in individuals with obesity compared to individuals with normal BMI [97].

A case-control study including patients with non-cardia stomach cancer and patients with EAC reported that the lowest quartile of ghrelin levels was associated with an approximately fivefold greater risk of non-cardia stomach adenocarcinoma and esophagogastric junctional adenocarcinoma when compared with the highest ghrelin level category [98]. The same patient population was also analyzed in terms of association between circulating levels of ghrelin and CRC risk, and an odds ratio of 1.57 (95\% CI 1.05-2.34; $P=0.03$ ) was reported for the lowest ghrelin quartile compared with the highest quartile [99]. Further analysis suggested that ghrelin could have distinct biological effects at different stages of the cancerogenic process [13, 99]; however, the results of another study on association between ghrelin and CRC were inconclusive [100]. As for other gastrointestinal cancers, there have been no studies conducted so far, investigating the link between ghrelin levels and cancer risk, although the bidirectional cross talk between ghrelin and hormones involved in energy regulation, such as leptin, adiponectin, and insulin, underlines the importance of this pathway in the role of obesity-related gastrointestinal carcinogenesis [101].

\section{Nonalcoholic Fatty Liver Disease (NAFLD)}

Overweight and obesity are associated with increased risk of nonalcoholic fatty liver disease (NAFLD), a spectrum of pathologies including variable degrees of simple steatosis, nonalcoholic steatohepatitis (NASH) and cirrhosis [102]. NASH is a major risk factor for liver fibrosis and can lead to HCC directly or indirectly through cirrhosis [61, 102]. Systemic and liver-specific molecular mechanisms involved in NASH, NAFLD and HCC include alterations in cellular lipid metabolism and insulin resistance [103]. Increased triglyceride content within hepatocytes, fibrosis, increased levels of free fatty acids and hepatocyte cell death all result in exacerbation of local inflammation and immune cell activation in the liver of individuals with obesity [104, 105]. As a result, this normally tolerogenic organ contains increased numbers of Kupffer cells, neutrophils, dendritic cells, Th17 CD4+ cells, CD8+ T cells, and NKT cells [106]. Studies of VAT and liver from patients with esophageal adenocarcinoma undergoing surgery showed parallel alterations in inflammatory pathways, including activation of Th17 cells as well as T cells expressing IFN- $\gamma$ and TNF- $\alpha$ [106]. These results suggest that VAT and the liver are closely linked in a local and systemic milieu of altered inflammatory and metabolic processes, which promotes carcinogenesis. NAFLD and NASH might be also risk factors for other gastrointestinal cancers, particularly CRC. A retrospective study conducted in South Korea reported that NAFLD was positively related to CRC risk in men (HR 2.01; 95\% CI 1.10-3.68) [107], whereas a cross-sectional study undertaken in Hong Kong reported that NASH was associated with an increased prevalence of colorectal adenomas (OR 4.89; 95\% CI 2.04-11.70) and advanced neoplasms (OR 5.34; 95\% CI 1.92-14.84) [108].

\section{Gastroesophageal Reflux Disease (GERD)}

Overweight and obesity are associated with 40-90\% higher risk of the symptoms of GERD, compared with normal weight $[109,110]$. Symptoms of GERD were associated with a fivefold-to-sevenfold higher risk of esophageal carcinoma (EAC) $[111,112]$. GERD was also associated with increased cardia stomach cancer risk in some studies [113-115].

\section{Cancer Stem Cell (CSC)}

Cancer stem cell (also termed tumor-initiating cell) hypothesis postulates that tumors originate through dysregulation of the physiological process of cell self-renewal [116], resulting in the aberrant replication and differentiation characteristic of variety of gastrointestinal cancers [117-120]. Evidence suggests a link between CSCs and excess adiposity, although its nature is not fully understood [121, 122]. In one study, it was shown that disease-free individuals with obesity had fivefold higher frequency of circulating progenitor cells $(P=0.0019)$ and a tenfold higher frequency of circulating mesenchymal stromal progenitor cells $(P=0.0021)$ than lean individuals [122]. It seems that obesity-associated chronic inflammation might promote the recruitment and mobilization of peripheral blood progenitor cells to various pathological sites for regeneration of tissues damaged by generated reactive oxygen species, reactive nitrogen species, lipid peroxidation products, etc. Prolonged exposure of progenitor cells to these mutagenic factors and pro-inflammatory cytokines might drive the conversion into CSCs. CSCs possess two main properties: the ability to self-renew and the ability to differentiate into heterogenous lineages of cancer cells that comprise the tumor [123].

\section{Conclusions}

The prevalence of obesity has increased dramatically in the past three decades and so the burden of cancers that are attributable to the prevalence of excessive adiposity. A growing body of evidence supports a relationship between 
obesity and elevated risks of gastrointestinal cancer development. Currently, three main hypotheses explaining the link between excess adiposity and gastrointestinal cancer risk are being considered, including (i) altered insulin and IGF-1 signaling, (ii) obesity-associated chronic low-grade inflammation, and (iii) altered sex hormone metabolism, although new potential mechanisms emerge. In addition to promoting carcinogenesis, obesity might also affect the tumor biology of established cancers. For instance, poorer survival has been reported in patients with colon cancer and pancreatic cancer who are overweight or obese at the time of diagnosis $[124,125]$. The risk of dying is increased in both group of patients with overweight (OR 1.26, 95\% CI $0.94-1.69, P=0.04$ ) and with obesity (OR $1.86,95 \%$ CI $1.35-2.56, P<0.001)$ with pancreatic cancer and in men with obesity treated with adjuvant chemotherapy for colon cancer (OR 1.16, 95\% CI 1.01-1.33, $P=0.023$ ) [124, 125]. These data suggest strongly a negative association of excessive adiposity with gastrointestinal cancer outcomes, treatment effects, and prognosis. However, many important questions remain in our understanding of adiposity-related gastrointestinal tract carcinogenesis. These questions may be answered with the knowledge gathered in large-scale epidemiological studies applying new analytical methods, such as various omics technologies, such as genomics, epigenomics, transcriptomics, proteomics, and metabolomics, as well as Mendelian randomization, MRI scans, and molecular pathological epidemiology approaches. Simple diet and lifetime changes result in the loss of $4 \%$ of body weight on average, while bariatric surgery generally leads to $15-30 \%$ weight loss and is often associated with dysmetabolism resolution [126-129]. There is considerable indirect evidence from observational studies that weight loss in individuals with obesity reduces cancer risk [130-132]. A better understanding of biological mechanisms involved in adiposity-related gastrointestinal carcinogenesis might help to identify better biomarkers of gastrointestinal cancer risk and new preventive strategies.

\section{Compliance with ethical standards}

Conflict of interest The authors declare that they have no conflict of interest.

Open Access This article is distributed under the terms of the Creative Commons Attribution-NonCommercial 4.0 International License (http://creativecommons.org/licenses/by-nc/4.0/), which permits any noncommercial use, distribution, and reproduction in any medium, provided you give appropriate credit to the original author(s) and the source, provide a link to the Creative Commons license, and indicate if changes were made.

\section{References}

1. (NCD-RisC), N. R. F. C. Worldwide trends in body-mass index, underweight, overweight, and obesity from 1975 to 2016: a pooled analysis of 2416 population-based measurement studies in 128.9 million children, adolescents, and adults. Lancet. 2017;390:2627-2642.

2. Organization WH. Obesity and overweight. 2017. http://www. who.int/news-room/fact-sheets/detail/obesity-and-overweight. Accessed 20 Nov 2018.

3. Saltiel AR, Olefsky JM. Inflammatory mechanisms linking obesity and metabolic disease. J Clin Investig. 2017;127:1-4.

4. Iyengar NM, Gucalp A, Dannenberg AJ, Hudis CA. Obesity and cancer mechanisms: tumor microenvironment and inflammation. J Clin Oncol. 2016;34:4270-4276.

5. Howe LR, Subbaramaiah K, Hudis CA, Dannenberg AJ. Molecular pathways: adipose inflammation as a mediator of obesityassociated cancer. Clin Cancer Res. 2013;19:6074-6083.

6. Lauby-Secretan B, Scoccianti C, Loomis D, et al. Body fatness and cancer-viewpoint of the IARC Working Group. $N$ Engl $J$ Med. 2016;375:794-798.

7. WCRF-AICR. Diet, nutrition, physical activity and colorectal cancer. Continuous Update Project. 2017. http://www.wcrf.org/ sites/default/files/CUP\%20Colorectal\%20Report_2017_Digit al.pdf. Accessed 20 Nov 2018.

8. WCRF-AICR. Diet, nutrition, physical activity and liver cancer. Continuous Update Project. 2015. http://www.wcrf.org/ sites/default/files/Liver-Cancer-2015-Report.pdf. Accessed 20 Nov 2018.

9. WCRF-AICR. Diet, nutrition, physical activity and oesophageal cancer. Continuous Update Project. 2016. http://www. wcrf.org/sites/default/files/Oesophageal-cancer-report.pdf. Accessed 20 Nov 2018.

10. WCRF-AICR. Food, nutrition, physical activity, and the prevention of pancreatic cancer. Continuous Update Project. 2012. http://www.wcrf.org/sites/default/files/Pancreatic-Cance r-2012-Report.pdf. Accessed 20 Nov 2018.

11. WCRF-AICR. Diet, nutrition, physical activity and stomach cancer. Continuous Update Project. 2016. http://www.wcrf.org/ sites/default/files/Stomach-Cancer-2016-Report.pdf. Accessed 20 Nov 2018.

12. WCRF-AICR. Diet, nutrition, physical activity and gallbladder cancer. Continuous Update Project. 2015. http://www.wcrf. org/sites/default/files/Gallbladder-Cancer-2015-Report.pdf. Accessed 20 Nov 2018.

13. Ulrich CM, Himbert C, Holowatyj AN, Hursting SD. Energy balance and gastrointestinal cancer: risk, interventions, outcomes and mechanisms. Nat Rev Gastroenterol Hepatol. 2018; https://doi.org/10.1038/s41575-41018-40053-41572. (ahead of print).

14. Bijlsma MF, Sadanandam A, Tan P, Vermeulen L. Molecular subtypes in cancers of the gastrointestinal tract. Nat Rev Gastroenterol Hepatol. 2017;14:333-342.

15. Sawayama H, Ishimoto $T$, Sugihara $H$, et al. Clinical impact of the Warburg effect in gastrointestinal cancer. Int J Oncol. 2014;45:1345-1354.

16. Mayers JR, Torrence ME, Danai LV, et al. Tissue of origin dictates branched-chain amino acid metabolism in mutant Krasdriven cancers. Science. 2016;353:1161-1165.

17. Hanyuda A, Cao Y, Hamada T, et al. Body mass index and risk of colorectal carcinoma subtypes classified by tumor differentiation status. Eur J Epidemiol. 2017;32:393-407.

18. Fu Y, Liu S, Yin S, et al. The reverse Warburg effect is likely to be an Achilles' heel of cancer that can be exploited for cancer therapy. Oncotarget. 2017;8:57813-57825. 
19. Wilde L, Roche M, Domingo-Vidal M, et al. Metabolic coupling and the Reverse Warburg Effect in cancer: implications for novel biomarker and anticancer agent development. Semin Oncol. 2017;44:198-203.

20. Bezemer ID, Rinaldi S, Dossus L, et al. C-peptide, IGF-I, sex-steroid hormones and adiposity: a cross-sectional study in healthy women within the European Prospective Investigation into Cancer and Nutrition (EPIC). Cancer Causes Control. 2005; 16:561-572.

21. Pollak MN, Schernhammer ES, Hankinson SE. Insulin-like growth factors and neoplasia. Nat Rev Cancer. 2004;4:505-518.

22. Pollak M. The insulin and insulin-like growth factor receptor family in neoplasia: an update. Nat Rev Cancer. 2012;12:159-169.

23. Tran TT, Naigamwalla D, Oprescu AI, et al. Hyperinsulinemia, but not other factors associated with insulin resistance, acutely enhances colorectal epithelial proliferation in vivo. Endocrinology. 2006;147:1830-1837.

24. Belfiore A, Malaguarnera R, Vella V, et al. Insulin receptor isoforms in physiology and disease: an updated view. Endocr Rev. 2017;38:379-431.

25. Pugeat M, Crave JC, Elmidani M, et al. Pathophysiology of sex hormone binding globulin (SHBG): relation to insulin. $J$ Steroid Biochem Mol Biol. 1991;40:841-849.

26. Schoen RE, Tangen CM, Kuller LH, et al. Increased blood glucose and insulin, body size, and incident colorectal cancer. J Natl Cancer Inst. 1999;91:1147-1154.

27. Limburg PJ, Stolzenberg-Solomon RZ, Vierkant RA, et al. Insulin, glucose, insulin resistance, and incident colorectal cancer in male smokers. Clin Gastroenterol Hepatol. 2006;2006:1514-1521.

28. Gunter MJ, Hoover DR, Yu H, et al. Insulin, insulin-like growth factor-I, endogenous estradiol, and risk of colorectal cancer in postmenopausal women. Can Res. 2008;68:329-337.

29. Kaaks R, Toniolo P, Akhmedkhanov A, et al. Serum C-peptide, insulin-like growth factor (IGF)-I, IGF-binding proteins, and colorectal cancer risk in women. J Natl Cancer Inst. 2000;92:1592-1600.

30. Wei EK, Ma J, Pollak MN, et al. A prospective study of C-peptide, insulin-like growth factor-I, insulin-like growth factor binding protein-1, and the risk of colorectal cancer in women. Cancer Epidemiol Biomark Prev. 2005;14:850-855.

31. Otani T, Iwasaki M, Sasazuki S, Inoue M, Tsugane S, J. P. H. C.-b. P. S. Group. Plasma C-peptide, insulin-like growth factor-I, insulin-like growth factor binding proteins and risk of colorectal cancer in a nested case-control study: the Japan public health center-based prospective study. Int J Cancer. 2007;120:2007-2012.

32. Jenab M, Riboli E, Cleveland RJ, et al. Serum C-peptide, IGFBP-1 and IGFBP-2 and risk of colon and rectal cancers in the European Prospective Investigation into Cancer and Nutrition. Int J Cancer. 2007;121:368-376.

33. Chen L, Li L, Wang Y, et al. Circulating C-peptide level is a predictive factor for colorectal neoplasia: evidence from the meta-analysis of prospective studies. Cancer Causes Control. 2013;224:1837-1847.

34. Murphy N, Cross AJ, Abubakar M, et al. A Nested casecontrol study of metabolically defined body size phenotypes and risk of colorectal cancer in the European Prospective Investigation into Cancer and Nutrition (EPIC). PLoS Med. 2016;13:e1001988.

35. Wolpin BM, Bao Y, Qian ZR, et al. Hyperglycemia, insulin resistance, impaired pancreatic $\beta$-cell function, and risk of pancreatic cancer. J Natl Cancer Inst. 2013;105:1027-1035.

36. Carreras-Torres R, Johansson M, Gaborieau V, et al. The role of obesity, type 2 diabetes, and metabolic factors in pancreatic cancer: a Mendelian Randomization Study. J Natl Cancer Inst. 2017;109:djx012.

37. Grote VA, Rohrmann S, Nieters A, et al. Diabetes mellitus, glycated haemoglobin and C-peptide levels in relation to pancreatic cancer risk: a study within the European Prospective Investigation into Cancer and Nutrition (EPIC) cohort. Diabetologia. 2011;54:3037-3046.

38. Aleksandrova $\mathrm{K}$, Boeing $\mathrm{H}$, Nöthlings $\mathrm{U}$, et al. Inflammatory and metabolic biomarkers and risk of liver and biliary tract cancer. Hepatology. 2014;60:858-871.

39. Hidaka A, Sasazuki S, Goto A, et al. Plasma insulin, C-peptide and blood glucose and the risk of gastric cancer: the Japan Public Health Center-based prospective study. Int J Cancer. 2015;136:1402-1410.

40. Valentinis B, Baserga R. IGF-I receptor signalling in transformation and differentiation. Mol Pathol. 2001;54:133-137.

41. Rinaldi S, Cleveland R, Norat T, et al. Serum levels of IGFI, IGFBP-3 and colorectal cancer risk: results from the EPIC cohort, plus a meta-analysis of prospective studies. Int J Cancer. 2010;126:1702-1715.

42. Reilly SM, Saltiel AR. Adapting to obesity with adipose tissue inflammation. Nat Rev Endocrinol. 2017;13:633-643.

43. Maurizi G, Della Guardia L, Maurizi A, Poloni A. Adipocytes properties and crosstalk with immune system in obesity-related inflammation. J Cell Physiol. 2018;233:88-97.

44. Mraz M, Haluzik M. The role of adipose tissue immune cells in obesity and low-grade inflammation. $J$ Endocrinol. 2014;222:R113-R127.

45. Stefan N, Häring HU, Schulze MB. Metabolically healthy obesity: the low-hanging fruit in obesity treatment? Lancet Diebetes Endocrinol. 2018;6:249-258.

46. Phillips CM. Metabolically healthy obesity across the life course: epidemiology, determinants, and implications. Ann N Y Acad Sci. 2017;1391:85-100.

47. Hanahan D, Weinberg RA. Hallmarks of cancer: the next generation. Cell. 2011;144:646-674.

48. Pikarsky E, Porat RM, Stein I, et al. NF-kappaB functions as a tumour promoter in inflammation-associated cancer. Nature. 2004;431:461-466.

49. Greten FR, Eckmann L, Greten TF, et al. IKKbeta links inflammation and tumorigenesis in a mouse model of colitis-associated cancer. Cell. 2004;118:285-296.

50. Crusz SM, Balkwill FR. Inflammation and cancer: advances and new agents. Nat Rev Clin Oncol. 2015;12:584-596.

51. Himbert C, Delphan M, Scherer D, Bowers LW, Hursting S, Ulrich CM. Signals from the adipose microenvironment and the obesity-cancer link-a systematic review. Cancer Prev Res. 2017;10:494-506.

52. Meza-Perez S, Randall TD. Immunological functions of the omentum. Trends Immunol. 2017;38:526-536.

53. Kabir M, Catalano KJ, Ananthnarayan S, et al. Molecular evidence supporting the portal theory: a causative link between visceral adiposity and hepatic insulin resistance. Am J Physiol Endocrinol Metab. 2005;288:E454-E461.

54. Ju C, Tacke F. Hepatic macrophages in homeostasis and liver diseases: from pathogenesis to novel therapeutic strategies. Cell Mol Immunol. 2016;13:316-327.

55. Item F, Konrad D. Visceral fat and metabolic inflammation: the portal theory revisited. Obes Rev Suppl. 2012;2:30-39.

56. Zhou B, Shu B, Yang J, Liu J, Xi T, Xing Y. C-reactive protein, interleukin-6 and the risk of colorectal cancer: a meta-analysis. Cancer Causes Control. 2014;25:1397-1405.

57. Nimptsch K, Aleksandrova K, Boeing H, et al. Association of CRP genetic variants with blood concentrations of C-reactive protein and colorectal cancer risk. Int J Cancer. 2015;136:1181-1192. 
58. Fasshauer M, Klein J, Neumann S, Eszlinger M, Paschke R. Hormonal regulation of adiponectin gene expression in 3T3-L1 adipocytes. Biochem Biophys Res Commun. 2002;25:1084-1089.

59. Wei EK, Giovannucci E, Fuchs CS, Willett WC, Mantzoros CS. Low plasma adiponectin levels and risk of colorectal cancer in men: a prospective study. J Natl Cancer Inst. 2005;97:1688-1694.

60. Riondino S, Roselli M, Palmirotta R, Della-Morte D, Ferroni P, Guadagni F. Obesity and colorectal cancer: role of adipokines in tumor initiation and progression. World J Gastroenetrol. 2014;20:5177-5190.

61. Renehan AG, Zwahlen M, Egger M. Adiposity and cancer risk: new mechanistic insights from epidemiology. Nat Rev Cancer. 2015;15:484-498.

62. Dalamaga M, Diakopoulos KN, Mantzoros CS. The role of adiponectin in cancer: a review of current evidence. Endocr Rev. 2012;33:547-594.

63. Pérez-Pérez A, Vilariño-García T, Fernández-Riejos P, MartínGonzález J, Segura-Egea JJ, Sánchez-Margalet V. Role of leptin as a link between metabolism and the immune system. Cytokine Growth Factors Rev. 2017;35:71-84.

64. Stattin P, Lukanova A, Biessy C, et al. Obesity and colon cancer: does leptin provide a link? Int J Cancer. 2004;19:149-152.

65. Rose DP, Komninou D, Stephenson GD. Obesity, adipocytokines, and insulin resistance in breast cancer. Obes Rev. 2004;5:153-165.

66. Vansaun MN. Molecular pathways: adiponectin and leptin signaling in cancer. Clin Cancer Res. 2013;19:1926-1932.

67. Ho GY, Wang T, Gunter MJ, et al. Adipokines linking obesity with colorectal cancer risk in postmenopausal women. Can Res. 2012;72:3029-3037.

68. Aleksandrova K, Boeing H, Jenab M, et al. Leptin and soluble leptin receptor in risk of colorectal cancer in the European Prospective Investigation into cancer and nutrition cohort. Can Res. 2012;72:5328-5337.

69. Bao Y, Giovannucci EL, Kraft P, et al. A prospective study of plasma adiponectin and pancreatic cancer risk in five US cohorts. J Natl Cancer Inst. 2013;105:95-103.

70. Ohishi W, Cologne JB, Fujiwara S, et al. Serum interleukin-6 associated with hepatocellular carcinoma risk: a nested casecontrol study. Int J Cancer. 2014;134:154-163.

71. Group., E. H. a. B. C. C., Key TJ, Appleby PN, et al. Circulating sex hormones and breast cancer risk factors in postmenopausal women: reanalysis of 13 studies. $\mathrm{Br} J$ Cancer. 2011;105:709-722.

72. Wallace IR, McKinley MC, Bell PM, Hunter SJ. Sex hormone binding globulin and insulin resistance. Clin Endocrinol. 2013;78:321-329.

73. Hartman J, Edvardsson K, Lindberg K, et al. Tumor repressive functions of estrogen receptor beta in SW480 colon cancer cells. Can Res. 2009;69:6100-6106.

74. Konduri S, Schwarz RE. Estrogen receptor beta/alpha ratio predicts response of pancreatic cancer cells to estrogens and phytoestrogens. J Surg Res. 2007;140:55-66.

75. Castiglione F, Taddei A, Rossi Degl'Innocenti D, et al. Expression of estrogen receptor beta in colon cancer progression. Diagn Mol Pathol. 2008;17:231-236.

76. Armstrong CM, Allred KF, Weeks BR, Chapkin RS, Allred CD. Estradiol has differential effects on acute colonic inflammation in the presence and absence of estrogen receptor $\beta$ expression. Dig Dis Sci. 2017;62:1977-1984. https://doi.org/10.1007/s1062 0-017-4631-x.

77. Herder C, Peltonen M, Svensson PA, et al. Adiponectin and bariatric surgery: associations with diabetes and cardiovascular disease in the Swedish Obese Subjects Study. Diabetes Care. 2014;37:1401-1409.
78. Clendenen TV, Koenig KL, Shore RE, Levitz M, Arslan AA, Zeleniuch-Jacquotte A. Postmenopausal levels of endogenous sex hormones and risk of colorectal cancer. Cancer Epidemiol Biomark Prev. 2009;18:275-281.

79. Lin JH, Zhang SM, Rexrode KM, et al. Association between sex hormones and colorectal cancer risk in men and women. Clin Gastroenterol Hepatol. 2013;11:419-424.e1.

80. Camargo MC, Goto Y, Zabaleta J, Morgan DR, Correa P, Rabkin CS. Sex hormones, hormonal interventions, and gastric cancer risk: a meta-analysis. Cancer Epidemiol Biomark Prev. 2012;21:20-38.

81. Sukocheva OA, Li B, Due SL, Hussey DJ, Watson DI. Androgens and esophageal cancer: what do we know? World J Gastroenetrol. 2015;21:6146-6156.

82. Petrick JL, Falk RT, Hyland PL, et al. Association between circulating levels of sex steroid hormones and esophageal adenocarcinoma in the FINBAR Study. PLOS ONE. 2018;13:e0190325.

83. Andrén-Sandberg A, Johansson J. Influence of sex hormones on pancreatic cancer. Int J Pancreatol. 1990;7:167-176.

84. Lukanova A, Becker S, Hüsing A, et al. Prediagnostic plasma testosterone, sex hormone-binding globulin, IGF-I and hepatocellular carcinoma: etiological factors or risk markers? Int $J$ Cancer. 2014;134:164-173.

85. Castaner O, Goday A, Park YM, et al. The gut microbiome profile in obesity: a systematic review. Int J Endocrinol. 2018; https ://doi.org/10.1155/2018/4095789. (ahead of print).

86. O'Keefe SJ. Diet, microorganisms and their metabolites, and colon cancer. Nat Rev Gastroenterol Hepatol. 2016;13:691-706.

87. Thangaraju M, Cresci GA, Liu K, et al. GPR109A is a G-protein-coupled receptor for the bacterial fermentation product butyrate and functions as a tumor suppressor in colon. Can Res. 2009;69:2826-2832.

88. Cani PD, Jordan BF. Gut microbiota-mediated inflammation in obesity: a link with gastrointestinal cancer. Nat Rev Gastroenterol Hepatol. 2018;. https://doi.org/10.1038/s41575-41018 -40025-41576. (ahead of print).

89. Cani PD, Bibiloni R, Knauf C, et al. Changes in gut microbiota control metabolic endotoxemia-induced inflammation in high-fat diet-induced obesity and diabetes in mice. Diabetes. 2008;57:1470-1481.

90. Damms-Machado A, Louis S, Schnitzer A, et al. Gut permeability is related to body weight, fatty liver disease, and insulin resistance in obese individuals undergoing weight reduction. Am J Clin Nutr. 2017;105:127-135.

91. Boulangé CL, Neves AL, Chilloux J, Nicholson JK, Dumas ME. Impact of the gut microbiota on inflammation, obesity, and metabolic disease. Genome Med. 2016;8:42.

92. Neal MD, Leaphart C, Levy R, et al. Enterocyte TLR4 mediates phagocytosis and translocation of bacteria across the intestinal barrier. J Immunol. 2006;176:3070-3079.

93. Ghoshal S, Witta J, Zhong J, de Villiers W, Eckhardt E. Chylomicrons promote intestinal absorption of lipopolysaccharides. J Lipid Res. 2009;50:90-97.

94. Lassenius MI, Pietiläinen KH, Kaartinen K, et al. Bacterial endotoxin activity in human serum is associated with dyslipidemia, insulin resistance, obesity, and chronic inflammation. Diabetes Care. 2011;34:1809-1815.

95. Cani PD, Amar J, Iglesias MA, et al. Metabolic endotoxemia initiates obesity and insulin resistance. Diabetes. 2007;56:1761-1772.

96. Pradhan G, Samson SL, Sun Y. Ghrelin: much more than a hunger hormone. Curr Opin Clin Nutr Metab Care. 2013;16:619-624.

97. Shiiya T, Nakazato M, Mizuta M, et al. Plasma ghrelin levels in lean and obese humans and the effect of glucose on ghrelin secretion. J Clin Endocrinol Metab. 2002;87:240-244. 
98. Murphy G, Kamangar F, Dawsey SM, et al. The relationship between serum ghrelin and the risk of gastric and esophagogastric junctional adenocarcinomas. J Natl Cancer Inst. 2011;103:1123-1129.

99. Murphy G, Cross AJ, Dawsey SM, et al. Serum ghrelin is associated with risk of colorectal adenocarcinomas in the ATBC study. Gut. 2017;67:1646-1651.

100. Sundkvist A, Myte R, Palmqvist R, Harlid S, Van Guelpen B. Plasma ghrelin is probably not a useful biomarker for risk prediction or early detection of colorectal cancer. Gut. 2018;. https:// doi.org/10.1136/gutjnl-2018-316110. (ahead of print).

101. Cui H, López M, Rahmouni K. The cellular and molecular bases of leptin and ghrelin resistance in obesity. Nat Rev Endocrinol. 2017;13:338-351.

102. Fabbrini E, Sullivan S, Klein S. Obesity and nonalcoholic fatty liver disease: biochemical, metabolic, and clinical implications. Hepatology. 2010;51:679-689.

103. Michelotti GA, Machado MV, Diehl AM. NAFLD, NASH and liver cancer. Nat Rev Gastroenterol Hepatol. 2013;10:656-665.

104. Narayanan S, Surette FA, Hahn YS. The immune landscape in nonalcoholic steatohepatitis. Immune Netw. 2016;16:147-158.

105. Conroy MJ, Galvin KC, Doyle SL, et al. Parallel profiles of inflammatory and effector memory $\mathrm{T}$ cells in visceral fat and liver of obesity-associated cancer patients. Inflammation. 2016;39:1729-1736.

106. O'Sullivan J, Lysaght J, Donohoe CL, Reynolds JV. Obesity and gastrointestinal cancer: the interrelationship of adipose and tumour microenvironments. Nat Rev Gastroenterol Hepatol. 2018;15:699-714.

107. Kim GA, Lee HC, Choe J, et al. Association between nonalcoholic fatty liver disease and cancer incidence rate. J Hepatol. 2017;. https://doi.org/10.1016/j.jhep.2017.1009.1012. (ahead of print).

108. Wong VW, Wong GL, Tsang SW, et al. High prevalence of colorectal neoplasm in patients with nonalcoholic steatohepatitis. Gut. 2011;60:829-836.

109. Hampel H, Abraham NS, El-Serag HB. Meta-analysis: obesity and the risk for gastroesophageal reflux disease and its complications. Ann Intern Med. 2005;143:199-211.

110. Friedenberg FK, Xanthopoulos M, Foster GD, Richter JE. The association between gastroesophageal reflux disease and obesity. Am J Gastroenterol. 2008;103:2111-2122.

111. Lagergren J, Bergström R, Lindgren A, Nyrén O. Symptomatic gastroesophageal reflux as a risk factor for esophageal adenocarcinoma. N Engl J Med. 1999;340:825-831.

112. Rubenstein JH, Taylor JB. Meta-analysis: the association of oesophageal adenocarcinoma with symptoms of gastro-oesophageal reflux. Aliment Pharmacol Ther. 2010;32:1222-1227.

113. Karimi P, Islami F, Anandasabapathy S, Freedman ND, Kamangar F. Gastric cancer: descriptive epidemiology, risk factors, screening, and prevention. Cancer Epidemiol Biomark Prev. 2014;23:700-713.

114. Figueroa JD, Terry MB, Gammon MD, et al. Cigarette smoking, body mass index, gastro-esophageal reflux disease, and non-steroidal anti-inflammatory drug use and risk of subtypes of esophageal and gastric cancers by P53 overexpression. Cancer Causes Control. 2009;20:361-368.

115. Derakhshan MH, Malekzadeh R, Watabe H, et al. Combination of gastric atrophy, reflux symptoms and histological subtype indicates two distinct aetiologies of gastric cardia cancer. Gut. 2008;57:298-305.

116. Quante M, Wang TC. Stem cells in gastroenterology and hepatology. Nat Rev Gastroenterol Hepatol. 2009;2009:724-737.

117. Sell S, Leffert HL. Liver cancer stem cells. J Clin Oncol. 2008;26:2800-2805.

118. Lee C, Dosch J, Simeone DM. Pancreatic cancer stem cells. $J$ Clin Oncol. 2008;26:2806-2812.

119. Takaishi S, Okumura T, Wang TC. Gastric cancer stem cells. $J$ Clin Oncol. 2008;26:2876-2882.

120. Zeuner A, Todaro M, Stassi G, De Maria R. Colorectal cancer stem cells: from the crypt to the clinic. Cell Stem Cell. 2014;15:692-705.

121. Zheng Q, Dunlap SM, Zhu J, et al. Leptin deficiency suppresses MMTV-Wnt-1 mammary tumor growth in obese mice and abrogates tumor initiating cell survival. Endocr Relat Cancer. 2011;18:491-503.

122. Bellows CF, Zhang Y, Simmons PJ, Khalsa AS, Kolonin MG. Influence of BMI on level of circulating progenitor cells. Obesity. 2011;19:1722-1726.

123. Shigdar S, Li Y, Bhattacharya S, et al. Inflammation and cancer stem cells. Cancer Lett. 2014;345:271-278.

124. Dignam JJ, Polite BN, Yothers G, et al. Body mass index and outcomes in patients who receive adjuvant chemotherapy for colon cancer. J Natl Cancer Inst. 2006;98:1647-1654.

125. Li D, Morris JS, Liu J, et al. Body mass index and risk, age of onset, and survival in patients with pancreatic cancer. JAMA. 2009;301:2553-2562.

126. Reges O, Greenland P, Dicker D, et al. Association of bariatric surgery using laparoscopic banding, Roux-en-Y gastric bypass, or laparoscopic sleeve gastrectomy vs usual care obesity management with all-cause mortality. JAMA. 2018;319:279-290.

127. Gloy VL, Briel M, Bhatt DL, et al. Bariatric surgery versus nonsurgical treatment for obesity: a systematic review and metaanalysis of randomised controlled trials. BMJ. 2013;234:f5934.

128. Leblanc ES, O'Connor E, Whitlock EP, Patnode CD, Kapka T. Effectiveness of primary care-relevant treatments for obesity in adults: a systematic evidence review for the U.S. Preventive Services Task Force. Ann Intern Med. 2011;155:434-447.

129. Colquitt JL, Pickett K, Loveman E, Frampton GK. Surgery for weight loss in adults. Cochrane Database Syst Rev. 2014;8:CD003641.

130. Sjöström L, Gummesson A, Sjöström CD, et al. Effects of bariatric surgery on cancer incidence in obese patients in Sweden (Swedish Obese Subjects Study): a prospective, controlled intervention trial. Lancet Oncol. 2009;10:653-662.

131. Adams TD, Stroup AM, Gress RE, et al. Cancer incidence and mortality after gastric bypass surgery. Obesity. 2009;17:796-802.

132. Schauer DP, Feigelson HS, Koebnick C, et al. Bariatric surgery and the risk of cancer in a large multisite cohort. Ann Surg. 2017;. https://doi.org/10.1097/sla.0000000000002525. (ahead of print)

Publisher's Note Springer Nature remains neutral with regard to jurisdictional claims in published maps and institutional affiliations. 